06

\title{
Процессы самоорганизации частиц детонационного алмаза на подложке в ходе конденсации углерода из парогазовой фазы
}

\author{
() В.А. Плотников, Б.Ф. Демьянов, С.В. Макаров, А.И. Зырянова
}

Алтайский государственный университет, Барнаул, Россия

E-mail: plotnikov@phys.asu.ru

Поступило в Редакцию 26 июля 2018г.

В окончательной редакции 10 января 2019г.

Принято к публикации 17 января 2019г.

\begin{abstract}
В композиционных углеродных пленках, полученных путем предварительного заселения аморфной подложки кристаллами детонационного наноалмаза и последующей конденсации углерода из парогазовой фазы, происходят процессы упорядочения островковой структуры. Эти процессы наблюдаются уже при заселении подложки алмазными центрами роста и проявляются в возникновении структурной периодичности островков. Установлено, что конденсация углерода на заселенную подложку сопровождается эволюцией островковой структуры первичных центров роста, заключающейся в формировании гексагональной упаковки островков, размер которых увеличился на два порядка. Все эти структурные особенности формирования композиционной алмазно-углеродной пленки свидетельствуют о протекании процессов самоорганизации в системе алмазных островков при конденсации атомов углерода и взаимодействии их с первичными кристаллами алмаза.
\end{abstract}

DOI: 10.21883/PJTF.2019.07.47540.17477

Открытие большого числа новых аллотропных модификаций углерода привело к созданию материалов с широким диапазоном физических и механических свойств [1]. Такие материалы, как алмаз, нанотрубки, фуллерены, аморфные углеродные пленки, обладают уникальным сочетанием свойств: высокой химической, термической и радиационной стойкостью, высокой твердостью и износостойкостью, низким коэффициентом термического расширения, малой теплоемкостью, высокой теплопроводностью, большой шириной запрещенной зоны, прозрачностью в широком диапазоне спектра. В основе классификации таких углеродных аллотропов лежит свойство гибридизации валентных орбиталей [2].

Другая классификация углеродных материалов основана на количестве ближайших атомов (2, 3, 4), с которыми каждый атом образует ковалентные связи [3]. На основе разработанных классификаций можно проектировать углеродные наноструктуры, которые перспективны для создания материалов с заданными физико-механическими свойствами. Так, при использовании детонационного наноалмаза можно формировать углеродные композиционные структуры с квантовыми точками [4]. Если композиционная углеродная структура сформирована как тонкопленочная, то отмечается высокая эластичность и высокие трибологические характеристики пленки, являющиеся следствием самоорганизации ее структуры [5]. Важно отметить, что углерод в композитах с алмазом позволяет управлять многими свойствами, такими как теплопроводность, электропроводность, магнетизм [6].

Композитные и гибридные углеродные материалы, обладая свойством самоорганизации, могут формировать сверхрешетки из наноразмерных частиц, включенных в однородную матрицу. В связи с этим детонационный наноалмаз может быть основным элементом в углеродных композиционных структурах, в которых процесс самоорганизации является базовым, так как позволяет контролировать свойства системы как размером сверхрешетки, так и свойствами наночастицы [7]. Однако здесь наблюдаются проблемы, одной из которых является обеспечение высокой периодичности сверхструктур самоорганизации и, следовательно, устойчивости свойств углеродных композитов.

Процессы самоорганизации могут приводить к образованию упорядоченных структур, обладающих элементами симметрии [8]. Например, в системе хаотически ориентированных частиц детонационного алмаза при воздействии высоких температур и давлений наблюдается образование крупных (до $80 \mathrm{~nm}$ ) алмазных частиц декаэдрической и икосаэдрической огранок [8]. Образование таких частиц алмаза в условиях термобарического воздействия осуществлялось путем упорядоченной самосборки исходных частиц, т.е. элементами самоорганизации являются исходные наночастицы. В настоящее время установлено, что рост алмазных кристаллов в условиях высокого давления и высокой температуры в смеси нанокристаллов детонационного алмаза с предельным ациклическим углеводородом осуществлялся по механизму ориентированного присоединения как отдельных атомов углерода, так и малых кластеров [9].

Явление самоорганизации наночастиц с образованием упорядоченных сверхструктур, по-видимому, носит более общий характер и наблюдается также при осаждении на подложку не только углеродных, но и металлических и полупроводниковых частиц. Так, при осаждении наночастиц $\mathrm{Au}$ и $\mathrm{CdSe}$ на углеродную пленку образуется 

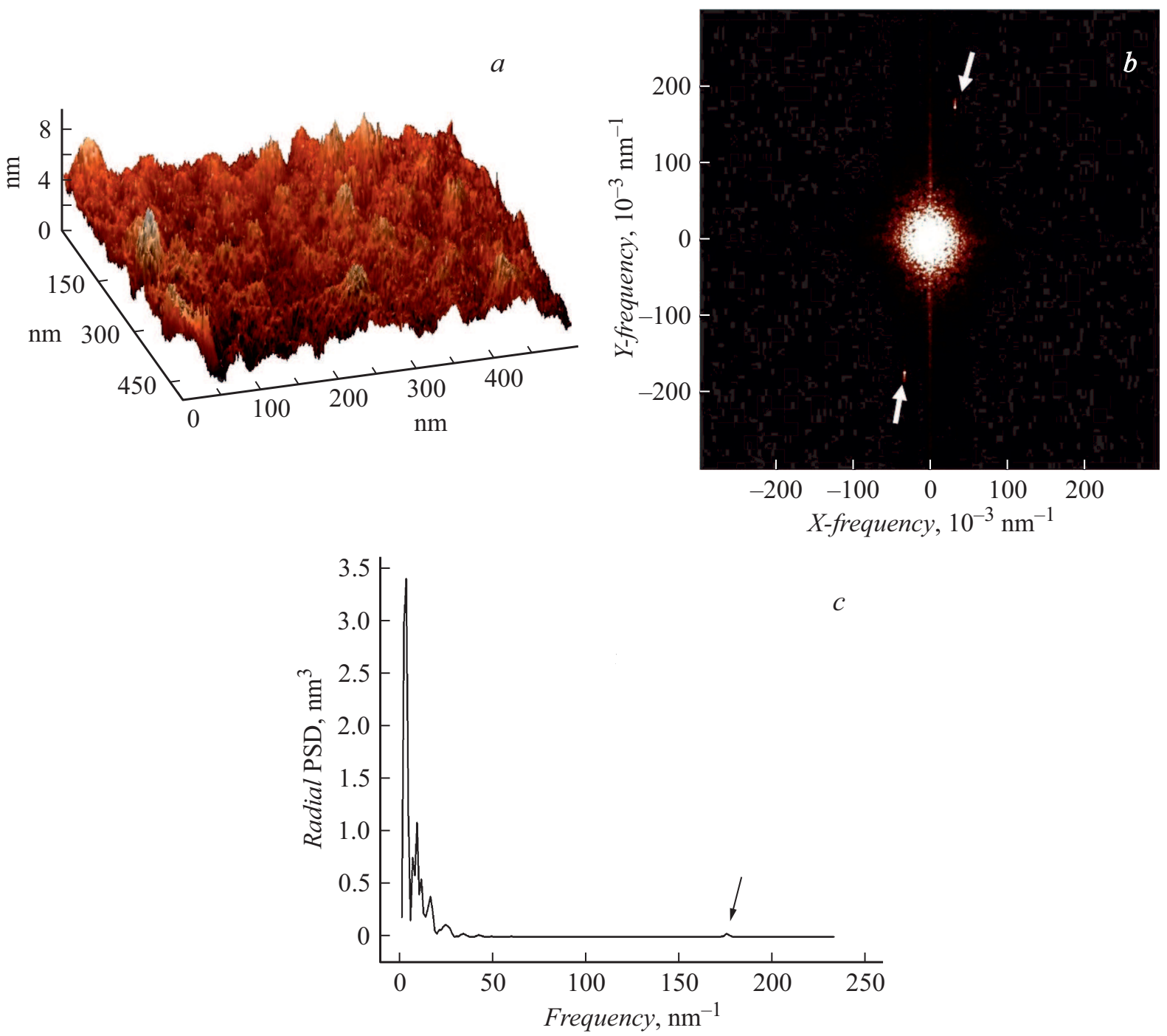

Рис. 1. Островковая структура пленки детонационного наноалмаза $(a)$, фурье-образ островковой структуры алмазной пленки $(b)$, функция радиального распределения $(c)$. Стрелками обозначены рефлексы периодической структуры с малым параметром периодичности.

плотноупакованная двумерная структура, представляющая собой „сверхрешетку“ с осью симметрии шестого порядка. Кроме того, кристаллы CdSe имели выраженную текстуру, при которой кристаллографическое направление [001] всех наночастиц было ориентировано перпендикулярно плоскости углеродной подложки [10].

Известно, что детонационный наноалмаз склонен к образованию цепочечных агрегатов: прочных первичных размером до $100 \mathrm{~nm}$ и менее прочных вторичных размером около $1 \mu \mathrm{m}$ [11]. Для формирования пленок из кристаллов детонационного наноалмаза необходимо диспергировать исходные конгломераты алмазных частиц до размеров единичных кристаллов. В работе приведены данные по структурам алмазных пленок, полученных путем лазерного диспергирования мишений из детонационного наноалмаза в вакууме и осаждения частиц на подложки из силикатного стекла.
Спрессованные мишени детонационного наноалмаза диспергировали в вакуумном объеме (остаточное давление $10^{-5} \mathrm{~mm} \mathrm{Hg}$ ) воздействием сфокусированного лазерного излучения с длиной волны $1064 \mathrm{~nm}$, энергией импульса $1-3 \mathrm{~J}$ и длительностью около $1 \mathrm{~ms}$. Из сформированного абляцией мишени факела частицы детонационного алмаза и более крупные конгломераты осаждались на подложки из силикатного стекла.

Островковая структура алмазной пленки, сформированной при переносе вещества мишени на подложку за счет абляции, приведена на рис. 1. Исследование островковой структуры осуществлялось с помощью сканирующего зондового микроскопа SOLVER NEXT. Исследование проводилось с помощью фурье-анализа островковой структуры пленки с использованием модуля обработки изображений Image Analysis P9, входящего в состав зондового микроскопа. Фурье-образ островко- 

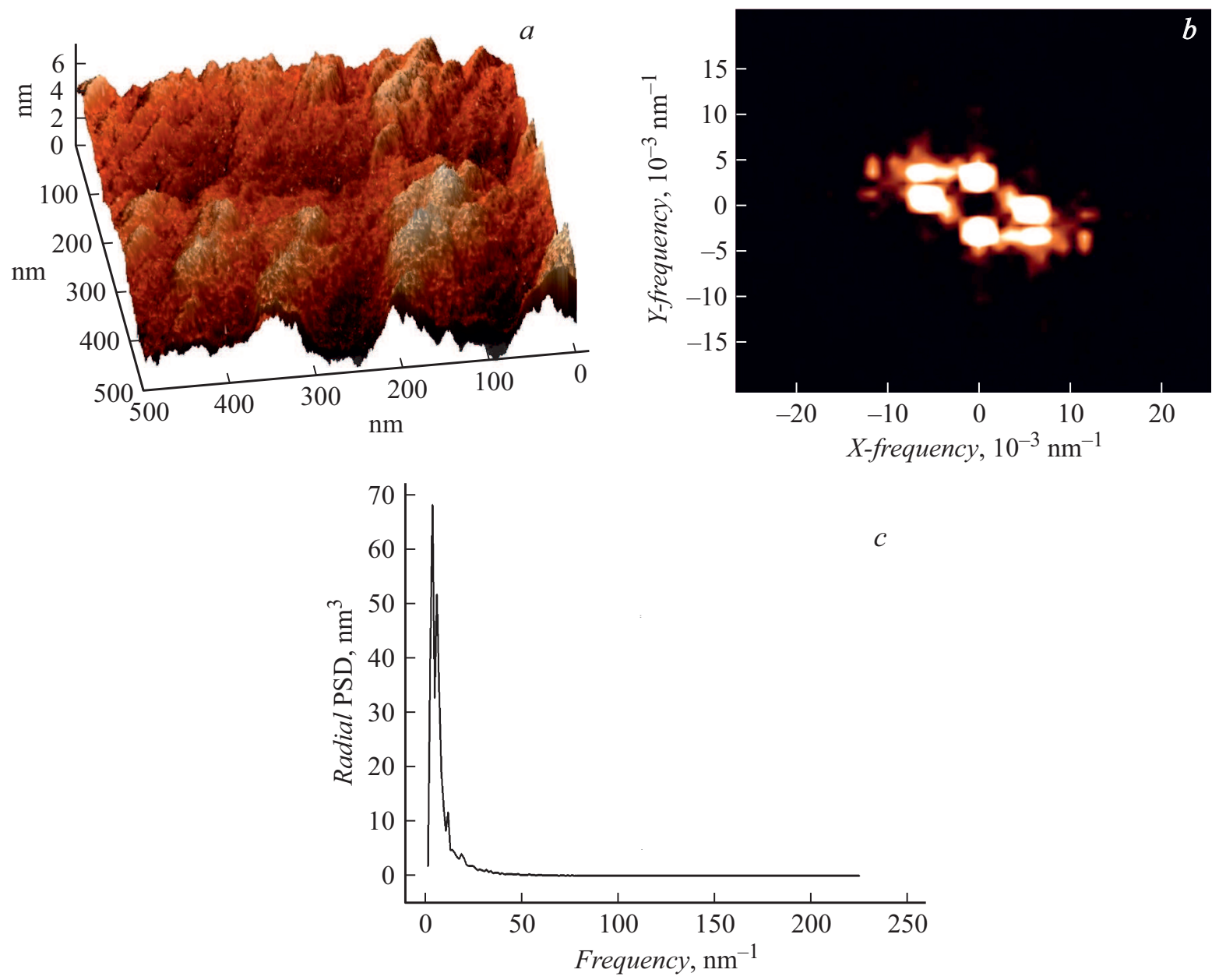

Рис. 2. Островковая структура композиционной пленки детонационный наноалмаз-конденсат углерода (a), фурье-образ островковой структуры алмазной пленки $(b)$, функция радиального распределения $(c)$.

вой структуры (рис. 1,b) помимо центрального пятна содержит два рефлекса, симметричных относительно центрального пятна, что свидетельствует о сосуществовании как крупных конгломератов, так и малых частиц, параметр периодичности которых на подложке составляет $5.7 \mathrm{~nm}$ (из анализа профиля сечения рис. 1,c). Таким образом, лазерное диспергирование (лазерная абляция) наноалмазной мишени позволяет заселить подложку центрами роста от единиц нанометров и до единиц микрометров. Существенно, что единичные нанокристаллы детонационного алмаза (средний размер нанокристаллов $4.5 \mathrm{~nm}$ ) плотно заселяют поверхность подложки (параметр периодичности $5.7 \mathrm{~nm})$.

Для снижения свободного пространства между частицами детонационного алмаза на предварительно заселенную нанокристаллами детонационного алмаза поверхность подложки был сконденсирован углерод из парогазовой фазы, полученной испарением графитовой мишени расфокусированным лазерным пучком с интенсивностью излучения не ниже $1.6 \cdot 10^{4} \mathrm{~W} / \mathrm{cm}^{2}$. На рис. 2 представлена островковая структура алмазной пленки после конденсации углерода. Приведенные дан- ные свидетельствуют о существенном изменении островковой структуры композиционной пленки. Размер островков значительно увеличился по сравнению с исходным. Фурье-анализ островковой структуры (рис. 2, $b$ ) свидетельствует о четкой периодичности в расположении частиц алмаза (согласно данным рис. 2, $c$, параметр периодичности, определенный по положению максимума функции радиального распределения, составил $285.2 \pm 0.6 \mathrm{~nm})$ и упорядоченной плотной упаковке алмазных островков на поверхности подложки гексагональной симметрии.

Таким образом, в ходе конденсации углерода на подложку, предварительно заселенную нуклеационными центрами с периодичностью $5.7 \mathrm{~nm}$, наблюдается разрастание наноразмерных частиц от $4.5 \mathrm{~nm}$ до частиц размером около $285.2 \mathrm{~nm}$. Совокупность таких частиц (островков) формирует плотноупакованную гексагональную островковую структуру алмазной пленки. Такая структура представляет собой поликристаллический агрегат из островков со средним размером $285.2 \mathrm{~nm}$, одинаково ориентированных относительно поверхности пленки. 


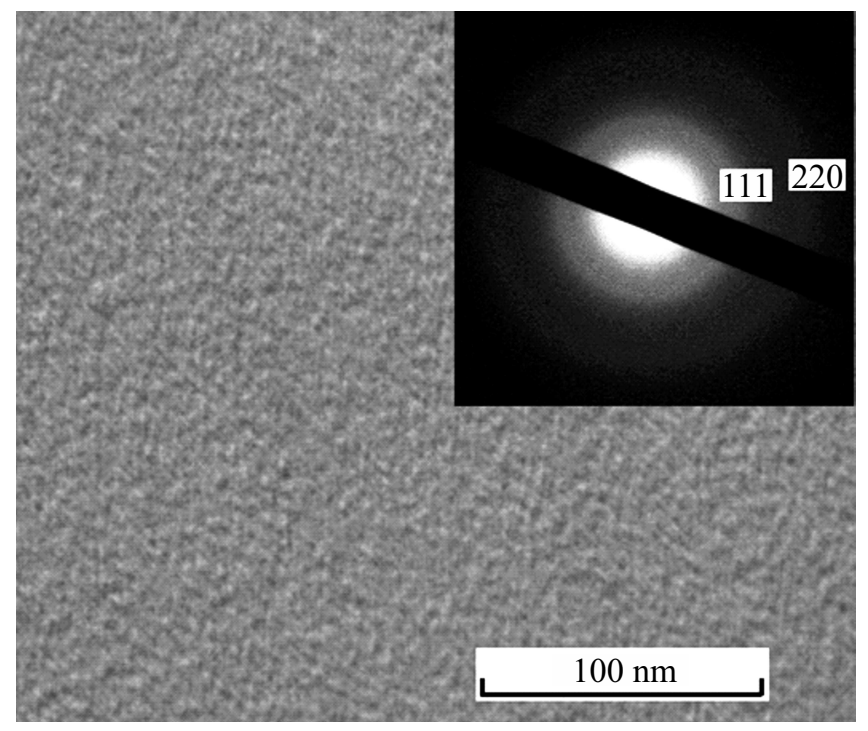

Рис. 3. Светлопольное электронно-микроскопическое изображение пленки и электронограмма от участка пленки (на вставке).

Можно полагать, что на границах раздела происходит превращение аморфного углерода, сконденсированного на подложку, в алмаз. Такой вывод не является неожиданным. В ряде публикаций отмечается [12], что наноалмаз размером около $4 \mathrm{~nm}$ термодинамически более стабилен, чем графит. В связи с этим представляется возможным переход части графитоподобного слоя углерода в алмазную структуру.

Воздействие лазера на мишень из детонационного алмаза не только приводит к ее диспергированию на фрагменты, но и сопровождается очисткой их от примесей, в первую очередь от летучих соединений [13], что приводит к активации незаполненных углеродных связей на границах. Представляется очевидным также, что испарение лазером графитовой мишени приводит к ионизации и возбуждению углерода в парогазовой фазе. Таким образом, в ходе конденсации углерод активно взаимодействует с исходными кристаллами наноалмаза, что приводит их к значительному росту. Нельзя исключить и объединение исходных кристаллов в монокристаллический блок, когда на границах раздела появляется большое число активированных атомов углерода. Все эти процессы и приводят к формированию упорядоченной структуры алмазных островков.

Наличие алмазной, точнее, алмазоподобной структуры углеродной пленки подтверждается исследованиями, проведенными с помощью просвечивающего электронного микроскопа Philips CM 30. На рис. 3 приведены структура и электронограмма исследуемого участка пленки. Расшифровка электронограмм показала, что кольца (дифракционные максимумы) соответствуют дифракции от плоскостей (111) и (220) решетки алмаза. Межплоскостные расстояния имеют значения $d_{111}=0.207 \mathrm{~nm}, d_{220}=0.119 \mathrm{~nm}$. При сравнении с межплоскостными расстояниями для крупнокристаллического алмаза $d_{111}=0.205 \mathrm{~nm}$ и $d_{220}=0.125 \mathrm{~nm}$ видно, что полученные величины отличаются от табличных значений. В пленке межплоскостное расстояние $d_{111}$ больше, a $d_{220}$ меньше величин для равновесной решетки. Такое искажение решетки является характерным для алмазоподобных тонких пленок. Например, в работе [14] исследованы тонкие углеродные пленки, полученные путем лазерного испарения и конденсации углерода, где значения межплоскостных расстояний равны $d_{111}=0.208 \mathrm{~nm}$, $d_{220}=0.117 \mathrm{~nm}$. В других исследованиях получены значения $d_{111}=0.207 \mathrm{~nm}$ [15]. Эти данные позволяют считать, что, скорее всего, межатомные расстояния не изменяются, длина связи $\mathrm{C}-\mathrm{C}$ остается постоянной, но изменяются углы между связями, как это имеет место в углеродных нанотрубках и фуллеренах [16].

Судя по конфигурации островков на рис. 2, $a$, можно считать, что на площади $0.25 \mu \mathrm{m}^{2}$ располагается около шести алмазных частиц, т. е. число частиц в $1 \mathrm{~cm}^{2}$ составляет около $24 \cdot 10^{8}$. Согласно современным представлениям, такая плотность частиц является оптимальной, например, для изготовления катодных материалов [17]. Таким образом, лазерный метод позволяет сформировать композит детонационный наноалмаз-углеродная алмазоподобная пленка с необходимой концентрацией структурных составляющих, определяющих его эмиссионные свойства.

Эксперименты по формированию композиционной пленки детонационный алмаз-конденсат углерода свидетельствуют об упорядоченной структуре островков, гексагонально плотноупакованных на поверхности аморфной подложки. Можно отметить существенный (на два порядка) рост исходных кристаллов детонационного алмаза при конденсации углерода из парогазовой фазы на предварительно заселенную центрами роста аморфную подложку. Эффекты упорядочения системы островков свидетельствуют об активации процессов самоорганизации при конденсации углерода на подложку, заселенную алмазными центрами роста.

\section{Список литературы}

[1] Hirsch A. // Nature Mater. 2010. V. 9. N 11. P. 868-871.

[2] Heimann R.B., Evsvukov S.E., Koga Y. // Carbon. 1997. V. 35. N 10. P. 1654-1658.

[3] Беленков Е.А., Ивановская В.В., Ивановский А.Л. Наноалмазы и родственные углеродные наноматериалы. Екатеринбург: УрО РАН, 2008. 169 c.

[4] Pichot V., Comet M., Risse B., Spitzer D. // Diamond Relat. Mater. 2014. V. 54. P. 59-63.

[5] Liu X., Yang J., Hao J., Zheng J., Gong Q. // Adv. Mater. 2012. V. 24. N 34. P. 4614-4617.

[6] Киселёв Н.И., Великанов Д.А., Корчагина С.Б., Петраковская Э.А., Васильев А.Д., Соловьёв Л.А., Балаев Д.А., Баюков О.А., Денисов И.А., Цегельник С.С., Ерёмин Е.В., Знак Д.А., Шайхутдинов К.А., Шубин А.А., Шестаков Н.П., Волков Н.В., Гордеев С.К., Белобров П.И. // Рос. хим. журн. 2012, T. LVI. № 1-2. С. 50-57. 
[7] Kondo D., Sato S., Awano Y. // Appl. Phys. Express. 2008. V. 1. N 7. P. 074003.

[8] Олейник Г.С., Котко А.В. // Письма в ЖТФ. 2008. Т. 34. B. 15. C. $55-62$.

[9] Кидалов С.В., Шахов Ф.М., Швидченко А.В., Смирнов А.Н., Соколов В.В., Яговкина М.А., Вуль А.Я. // Письма в ЖТФ. 2017. Т. 43. В. 1. С. 21-29.

[10] Zaporozhets M.A., Savilov S.V., Zhigalina O.M., Sul'yanov S.N., Volkov V.V., Nikolaichik V.I., Gubin S.P., Avilov A.S. // Cryst. Rep. 2012. V. 57. N 3. P. 426-433.

[11] Ершов А.П., Куперштох А.Л., Коломийчук В.Н. // Письма в ЖТФ. 1990. Т. 16. В. 3. С. $42-46$.

[12] Гордеев С.К., Коноплева Р.Ф., Чеканов В.А., Корчагина С.Б., Беляев С.П., Голосовский И.В., Денисов И.А., Белобров П.И. // ФТТ. 2013. Т. 55. В. 7. С. 1380-1385.

[13] Богданов Д.Г., Макаров С.В., Плотников В.А. // Письма в ЖТФ. 2012. Т. 38. В. 4. C. 89-95.

[14] Pappas D.L., Saenger K.L., Bruley J., Krakow W., Cuomo J.J., Gu T., Collins R.W. // J. Appl. Phys. 1992. V. 71. N 11. P. 5675-5684.

[15] Петров С.A. // Вестн. БГУ. Сер. 1. 2012. № 1. С. 43-45.

[16] Плотников В.А., Демьянов Б.Ф., Соломатин К.В., Макаров С.В., Ярцев В.И. // Фундаментальные проблемы современного материаловедения. 2013. Т. 10. № 1. С. 50 55.

[17] Ябаров Р.К., Котина Н.М. // Фундаментальные проблемы современного материаловедения. 2016. Т. 16. № 4. С. 534 539. 